\title{
Detection of Pathogenic Bacteria During Rhinovirus Infection is Associated with Increased Respiratory Symptoms and Exacerbations of Asthma
}

\author{
Kirsten M. Kloepfer, MD, MS ${ }^{a}$, Wai Ming Lee, PhD ${ }^{b}$, Tressa E. Pappas, BS ${ }^{b}$, Teresa Kang ${ }^{b}$, \\ Rose F. Vrtis, BS ${ }^{c}$, Michael D. Evans, MS ${ }^{d}$, Ronald E. Gangnon, PhD ${ }^{d}$, Yury A. Bochkov, \\ PhD $^{\mathrm{b}}$, Daniel J. Jackson, MD, Robert F. Lemanske Jr., MD ${ }^{\mathrm{b}, \mathrm{c}}$, and James E. Gern, MD ${ }^{\mathrm{b}, \mathrm{c}}$ \\ ${ }^{\text {aDepartment }}$ of Pediatrics, Indiana University School of Medicine \\ ${ }^{b}$ Department of Pediatrics, University of Wisconsin-Madison \\ 'Department of Medicine, University of Wisconsin-Madison \\ dDepartment of Biostatistics and Medical Informatics, University of Wisconsin-Madison
}

\begin{abstract}
Background-Detection of either viral or bacterial pathogens is associated with wheezing in children, however the influence of both bacteria and virus on illness symptoms has not been described.
\end{abstract}

Objective-We evaluated bacterial detection during peak RV season in children with and without asthma to determine if an association exists between bacterial infection and the severity of RV illnesses.

\begin{abstract}
Methods-308 children (166 with asthma, 142 without asthma) ages 4-12 years provided five consecutive weekly nasal samples during September, and scored cold and asthma symptoms daily. Viral diagnostics and quantitative PCR for Streptococcus pneumoniae, Haemophilus influenzae and Moraxella catarrhalis were performed on all nasal samples.
\end{abstract}

Results-Detection rates were 53\%, $17 \%$ and $11 \%$ for $H$. influenzae, S. pneumoniae and $M$. catarrhalis, respectively, with detection of RV increasing the risk of detecting bacteria within the same sample (OR 2.0, 95\% CI 1.4-2.7, p<0.0001) or the following week (OR 1.6 (1.1-2.4), $\mathrm{p}=0.02)$. In the absence of RV, S. pneumoniae was associated with increased cold symptoms (mean 2.7 (95\% CI 2.0-3.5) vs. $1.8(1.5-2.2), \mathrm{p}=0.006)$ and moderate asthma exacerbations (18\% $(12 \%-27 \%)$ vs. $9.2 \%(6.7 \%-12 \%), \mathrm{p}=0.006)$. In the presence of RV, S. pneumoniae was

\footnotetext{
(C) 2014 American Academy of Allergy, Asthma and Immunology. Published by Mosby, Inc. All rights reserved. Corresponding author: Kirsten M. Kloepfer MD, 705 Riley Hospital Drive, Indianapolis, IN 46202. Telephone number (317) 278-7860, Fax number (317) 278-7856, and kloepfer@iupui.edu.

Concept and design: JEG, RFL; Analysis and interpretation: KMK, WML, TEP, TK, RFV, MDE, REG, YAB, RFL, JEG; Drafting of manuscript for important intellectual content: KMK, JEG

Publisher's Disclaimer: This is a PDF file of an unedited manuscript that has been accepted for publication. As a service to our customers we are providing this early version of the manuscript. The manuscript will undergo copyediting, typesetting, and review of the resulting proof before it is published in its final citable form. Please note that during the production process errors may be discovered which could affect the content, and all legal disclaimers that apply to the journal pertain.
} 
associated with increased moderate asthma exacerbations (22\% (16\%-29\%) vs. $15 \%(11 \%-20 \%)$, $\mathrm{p}=0.01$ ). Furthermore, $M$. catarrhalis detected alongside RV increased the likelihood of experiencing cold and/or asthma symptoms compared to isolated detection of RV (OR 2.0 (1.04.1), $\mathrm{p}=0.04$ ). Regardless of RV status, $H$. influenzae was not associated with respiratory symptoms.

Conclusion-RV infection enhances detection of specific bacterial pathogens in children with and without asthma. Furthermore, these findings suggest that M. catarrhalis and S. pneumoniae contribute to the severity of respiratory illnesses, including exacerbations of asthma.

\section{Keywords}

Rhinovirus; bacteria; asthma

\section{INTRODUCTION}

There is mounting evidence that asthma is associated with changes in the airway microbiome. For example, detection of Streptococcus pneumoniae, Haemophilus influenzae and Moraxella catarrhalis within the upper airway in early infancy is associated with an increased risk of developing recurrent wheezing and then asthma. $(1,2)$ In addition, cultureindependent methods of bacteria detection demonstrate that Proteobacteria, a phylum of bacteria containing a majority of gram-negative bacteria, appeared more frequently in both nasal and bronchial samples in stable asthma, and are linked to increased bronchial hyperresponsiveness. (3-5) However, prospective studies have not utilized molecular methods of detection to analyze these bacteria between children with and without asthma.

Recently, we reported that $90 \%$ of children with asthma are infected with rhinoviruses (RV) during the month of September, and the severity of clinical illness varies from no symptoms to severe wheezing illnesses. (6) These findings strongly suggest that there are cofactors which affect the relationship between RV infection and illness, and suggest that airway bacteria might contribute in this regard. Furthermore, a recent study found an increase in invasive pneumococcal disease during peak RV activity. (7) We therefore hypothesized that detection of specific bacterial pathogens would be increased in children with asthma compared to children without asthma; and that co-detection of these bacteria with RV would be associated with increased respiratory symptoms compared to RV detection alone. To test these hypotheses, we prospectively obtained weekly specimens of nasal secretions from children with and without asthma during the fall of 2007-2009, and then compared detection of viruses and select bacteria to cold and asthma symptoms and moderate exacerbations of asthma.

\section{METHODS}

\section{Study subjects and design}

Children included in this analysis were enrolled in a larger study to determine genetic correlates with more severe RV illnesses ("RhinoGen"). Of the 383 children participating in RhinoGen, 308 children ages 4-12 years submitted samples during a peak RV season. Starting the first Saturday of September of 2007, 2008 or 2009, nasal samples were collected 
weekly for a total of five consecutive weeks. Children, with the help of their parents, were instructed to record URI and asthma symptoms, morning peak expiratory flow (PEF) and albuterol use on daily diary cards from one week prior to first nasal sample submission through one week following the final (fifth) sample submission. See online supplement for additional details about recruitment and inclusion criteria. This study was approved by the University of Wisconsin Human Subjects Committee and written informed consent was obtained from the parents.

\section{Procedures and Definitions}

At the first study visit, subjects were taught to collect samples of their own nasal mucus using a nose-blowing technique as previously described. $(6,8)$ These samples were analyzed for common respiratory viruses by Respiratory Multicode Assay, EraGen Biosciences, Madison, Wisconsin. (9)

Nasal samples were also analyzed for Streptococcus pneumoniae, Haemophilus influenzae and Moraxella catarrhalis by quantitative real-time PCR. DNA was extracted using the BiOstic Bacteremia DNA Isolation Kit (Mo Bio laboratories, Carlsbad, California). The quantitative Spn9802 PCR for the detection of S. pneumoniae (10) was combined with the P6 PCR for the detection of $H$. influenzae (11) and the copB PCR for the detection of $M$. catarrhalis (12) as previously described. All primers and probes were obtained from Applied Biosystems and the real-time PCR assay was performed in a 7300 Applied Biosystems instrument. We confirmed double and triple positive results obtained by Multicode assay by repeating qPCR with single target assays. Standard curves consisted of bacterial DNA extracted from known quantities of clinical isolates of each bacteria obtained from the University of Wisconsin Hospital Clinical Microbiology Laboratory, and PCR results are expressed as colony-forming-unit equivalents (CFUe).

Children scored cold and asthma symptom severity based on a 4-point scoring system (see Table 1 in the online data supplement). $(6,8)$ Moderate asthma exacerbations were defined as at least moderate asthma symptoms (score $\geq 2$ ) and either a decrease in PEF of at least $20 \%$ or increased use of albuterol $\geq 2$ days, in accordance with NHLBI and ATS definitions. $(13,14)$ Current asthma was diagnosed at study completion based on previously reported criteria. (15) Skin prick testing and total and allergen-specific IgE levels in plasma were performed upon enrollment (Unicap 100; Phadia, Uppsala, Sweden).

Children who collected at least 4 of 5 weekly nasal specimens and were missing less than $20 \%$ of diary card data were included in the analysis. A week was defined as the 7-day period surrounding ( \pm 3 days) the day of nasal specimen collection. Each week was designated as virus and/or bacteria positive or negative based on viral and/or bacteria detection. Cold and asthma symptom burdens for each week were calculated by summing the daily symptom scores across the week. An illness was defined as a period of two or more consecutive days of cold or asthma symptoms that did not contain any periods of consecutive asymptomatic days. All nasal samples obtained between 3 days prior to the first day of the illness and 3 days following the last day of the illness were considered to be associated with that illness. Cold and asthma symptom burdens for each illness were calculated by summing the daily symptom scores across the illness. 


\section{Statistical analysis}

Atopic status (positive by either specific IgE or skin prick test), race, and gender were compared by asthma status using the chi-square test for association. Age and FeNO were compared by asthma status using the Wilcoxon rank-sum test. FEV1, FVC, and FEV1/FVC were compared by asthma status using linear models that also included covariates for age, gender, race, and height. Viral infection and bacteria detection rates were compared by asthma status using logistic regression models, both univariate and adjusting for gender, race, and sensitization. Generalized linear mixed effect models with a random effect for subject to account for repeated measures within subjects were used to compare weekly symptom burdens and occurrences of moderate asthma exacerbations by virus and bacteria detection, and to assess whether infection with a given virus or bacteria increased or decreased susceptibility to another bacteria or virus during the same week or one week later. To assess the association between virus and/or bacteria detection and the occurrence of an illness, a matched pairs case-control design was used where each illness (case) was matched with an asymptomatic period (control) of the same length in another subject. Conditional logistic regression was then used to estimate odds ratios of illness occurrence with respect to virus and/or bacteria detection. A two-sided p-value $<0.05$ was regarded as statistically significant.

\section{RESULTS}

\section{Subject characteristics}

Of the 383 children enrolled in RhinoGen, 54 had insufficient quantity of nasal samples to allow analysis for both viruses and bacteria, while an additional 19 subjects did not submit at least four $(80 \%)$ of the five scheduled nasal samples, and 2 additional subjects failed to complete at least 40 days (80\%) of symptom diaries. Therefore a total of 308 subjects (80\%) were included in the final analysis (see Figure 1 in online supplement).

Of the 308 subjects enrolled, 166 (54\%) had current asthma. In comparing the groups there was no significant difference in age or baseline lung function; however, the asthma group had a higher rate of allergic sensitization, higher baseline FeNO values and contained more males and fewer Caucasians (Table 1).

\section{Identification of Pathogenic Bacteria}

The 308 subjects who completed the study submitted 1,394 nasal samples. 173 samples positive for other viruses were excluded from analysis, resulting in 867 (71\%) samples positive for bacteria and 481 (39\%) samples positive for RV. Of the bacteria detected, $H$. influenzae was detected most frequently (53\% of samples), followed by S. pneumoniae (17\%) and M. catarrhalis (11\%). Detection rates were similar between children regardless of asthma (Table 2) and allergic sensitization status (data not shown).

Examination of immunization records revealed that $95 \%$ of subjects were vaccinated with the full series of Haemophilus influenzae type B (HIB) vaccine, while $61 \%$ of subjects were vaccinated with the pneumococcal (PCV-7) vaccine. There were no differences in bacterial 
detection rates or symptom reporting based on pneumococcal vaccine status (data not shown).

\section{Bacterial Detection Associated with Viral Infection}

We next analyzed whether viral detection increased the likelihood for bacterial detection, or vice versa. $\mathrm{RV}$ detection increased the risk for detection of a bacterial pathogen in the same specimen (OR 2.0, 95\% CI 1.4-2.7, $\mathrm{p}<0.0001$ ) and for detection of bacteria the following week (OR 1.6 (1.1-2.4), $\mathrm{p}=0.02$; Table 3). In contrast, detection of bacteria did not increase the chance of viral detection the following week (OR $0.9(0.6-1.3), \mathrm{p}=0.42)$. Similarly, when examining each bacteria individually, RV was more likely to precede $S$. pneumoniae detection (OR 3.4 (2.0-5.5), p <0.0001), and M. catarrhalis detection (OR 3.7 (1.5-9.0), $\mathrm{p}=0.004)$. $\mathrm{RV}$ infection was also associated with an increased likelihood of concurrent detection of S. pneumoniae (OR 3.0 (2.1-4.3), $\mathrm{p}<0.0001$ ), with a similar trend for $M$. catarrhalis (OR 1.5 (1.0-2.3), $\mathrm{p}=0.08$ ). $\mathrm{RV}$ infection was also associated with greater quantities of $S$. pneumoniae and $H$. influenzae, with a similar trend observed for $M$. catarrhalis (Table 4).

\section{Time-Based Analysis of Bacteria Effects on Illness Severity}

We used two approaches to determine whether detection of bacteria was related to illness severity. First, we conducted a time-based analysis to determine whether detection of RV, bacteria, or both in a given week was related to the severity of cold symptoms during that same week. Compared to weeks with no pathogen detected (mean 1.8 (1.5-2.2)), cold symptom burden was significantly greater with either $S$. pneumoniae detection (mean 2.7 (2.0-3.5), $\mathrm{p}=0.006$ ) or RV infection (mean 3.3 (2.8-3.9), $\mathrm{p}<0.0001$, Figure 2B). In addition, concurrent detection of $S$. pneumoniae and RV was associated with increased cold symptoms (mean 3.8 (3.0-4.7), p $<0.0001$ ) even when compared to detection of $S$. pneumoniae alone ( $\mathrm{p}=0.02)$. Neither $M$ catarrhalis nor $H$. influenzae were associated with increased cold symptoms (Figures 1A \& C).

Next we compared pathogen detection to asthma symptoms. Compared to weeks with no pathogens (mean 1.6 (1.3-2.1)), asthma symptoms were increased when RV was detected together with either S. pneumoniae (mean $2.9(2.1-4.0), \mathrm{p}=0.0001$ ) or $M$. catarrhalis (mean 2.7 (1.8-4.0), $\mathrm{p}=0.01$ ), with a trend for increased symptoms with both RV and $S$. pneumoniae compared to RV alone ( $\mathrm{p}=0.08$, Figure $1 \mathrm{E})$. H. influenzae detection was not associated with increased asthma symptoms (Figures 1F).

We next compared detection of bacteria, either individually or in combination with a viral illness, to the prevalence of moderate asthma exacerbations. Compared to when no pathogen was detected (mean 9.2\% (6.7\%-12\%)), exacerbations were more frequent with detection of either RV (mean 15\% (11\%-20\%), p=0.0005) or S. pneumoniae (mean 18\% (12\%-27\%), $\mathrm{p}=0.006$, Figure $1 \mathrm{H})$. Weeks where RV and S. pneumoniae were detected together had the highest frequencies of exacerbations (mean $22 \%(16 \%-29 \%), p<0.0001$ ), and this combination was more likely to be associated with asthma exacerbation when compared to $\mathrm{RV}$ infection alone ( $\mathrm{p}=0.01)$. The presence of $M$. catarrhalis or $H$. influenzae did not increase the risk of asthma exacerbation (Figures $1 \mathrm{G} \& \mathrm{I}$ ). 
Finally, the associations between pathogens and study outcomes (cold symptoms, asthma symptoms, asthma exacerbations) did not differ by atopic status (interaction $\mathrm{p}$ values all $>0.2$.

\section{IIIness-Based Analysis of Bacteria Effects on IIIness Severity}

We also performed an illness-based analysis to determine if RV and/or bacteria detection influenced the probability of symptomatic illness, including moderate asthma exacerbations. For this analysis, illnesses were clinically defined by at least two consecutive days of respiratory symptoms (median 6 days, range $2-42$ days), and then pathogens detected during the illness were analyzed. Thus, an illness could be associated with no pathogens, RV, bacteria, or both (including sequential detection of more than one pathogen). Over the five weeks, 291 illnesses occurred; 11\% of illnesses were associated with RV alone, 30\% associated with bacteria detection, $49 \%$ associated with detection of both RV and bacteria, and $10 \%$ of illnesses were not associated with either pathogen. Each illness was then matched with an asymptomatic period of the same length, and probability of pathogen detection was compared. When detected as single pathogens, RV alone increased the risk of illness (OR 1.5 (1.0-2.3), $\mathrm{p}=0.03$ ), but this was not the case for any of the bacteria (Figure $3)$.

We next examined combinations of RV and specific bacteria and their relationships to illness (Figure 2A-C). Among all study subjects, illnesses were significantly associated with detection of RV together with either $M$. catarrhalis (OR 3.1 (1.6-6.4), $\mathrm{p}=0.001$ ) or $S$. pneumoniae (OR 2.2 (1.3-3.7), $\mathrm{p}=0.004$ ). Furthermore, detection of the combination of RV and $M$. catarrhalis (OR $2.0(1.0-4.1), \mathrm{p}=0.04)$ increased the likelihood of illness compared to solitary detection of RV. In contrast, the presence of $H$. influenzae in combination with $\mathrm{RV}$ was not associated with increased risk of illness.

Finally, we tested whether the combination of RV and bacteria was associated with increased illnesses with moderate asthma exacerbations. Exacerbations that were associated with RV together with M. catarrhalis (OR 7.1 (1.3-39), $\mathrm{p}=0.02$ ), S. pneumoniae (OR 4.2 (1.4-13), $\mathrm{p}=0.01$ ) or $H$. influenzae (OR $4.2(1.1-16), \mathrm{p}=0.04$ ) had the greatest risk of exacerbations (Figure 2D-F).

\section{DISCUSSION}

In this study we tested two hypotheses to determine the role of bacterial pathogens in RVinduced respiratory symptoms and exacerbations of asthma. First, we predicted that detection of bacterial pathogens would be increased in children with asthma compared to their non-asthmatic counterparts; however, this was not the case. We also hypothesized that common bacterial pathogens contribute to RV illness severity, and thus these bacteria would be more prevalent during RV illnesses than during asymptomatic RV infections. By prospectively monitoring viruses and bacteria at weekly intervals, we found several significant relationships between RV infections and detection of common bacterial pathogens. RV infection was associated with a greater probability of detecting bacteria within concurrent and subsequent nasal samples, and also an increase in the quantity of these bacteria. We then used two analytic strategies (time-based and illness-based) to compare 
pathogen detection to respiratory symptoms, and the results provide evidence that specific bacteria and RV and are both associated with respiratory and asthma symptoms. In the timebased analysis, S. pneumoniae was associated with moderate asthma exacerbations when detected either alone or together with RV; while our illness-based analysis demonstrates that illnesses associated with RV and S. pneumoniae, M. catarrhalis or H. influenza are associated with an increased risk of moderate exacerbations compared to illnesses without pathogen detection. These findings suggest that during RV infection, these specific bacterial pathogens are cofactors that contribute to the severity of respiratory symptoms, including $\mathrm{RV}$-induced exacerbations of asthma.

Regardless of the analytic approach, the detection of $H$. influenzae alone was generally not associated with greater symptoms. A previous study of 33 subjects using culture-based methods reported an association between $H$. influenzae in BAL samples and persistent wheezing in preschool children. (16) The differences in study results may be due to the differences in ages of the study populations, or it could be that $H$. influenza can contribute to respiratory symptoms in young children but this process is not related to RV infection.

Another possibility is only some $H$. influenza strains cause symptoms, and that our PCRbased methods could have detected a broader range of non-culturable strains of $H$. influenzae that are not associated with disease.

To our knowledge, this study was the first to prospectively follow both viral and bacterial infections in school age children with and without asthma. Bacterial pathogens were detected at higher rates than in previous studies, possibly due to our use of molecular techniques rather than culture based methods. $(1,2)$ Alternatively, since season can affect the detection of S. pneumoniae $(17,18)$ and M. catarrhalis, (19) the high rates of detection in our study may be related to sampling in the fall.

Bacteria were most likely to be detected when RV was present or in the week following RV infection. This relationship is in accordance with viral infections preceding bacterial infections in the middle ears, (20) sinuses, (21) and lungs. (22) Viral infections promote bacterial infections through several mechanisms, including induction of receptors used by bacteria to invade cells, (23) and disruption of epithelial barrier function. $(24,25)$ It is likely that RV utilizes some or all of these mechanisms to promote susceptibility to bacterial invasion. (26) In addition, microbial components can activate Toll-like receptors (TLRs), prompting epithelial cells and leukocytes to release inflammatory cytokines and mediators. Therefore, it is possible that children infected with both RV and bacteria experience greater airway inflammation that in turn contributes to symptoms and asthma exacerbations.

This study has a number of unique advantages, and some limitations that should be considered in interpreting these data. The prospective study design allowed us to monitor children for rates of RV infection, bacterial detection and associated cold and asthma symptoms. For detection of RV and bacteria, we utilized sensitive PCR-based diagnostics. (9) Also, we used a simple sample collection and scoring system to encourage adherence. The scoring system has proven to be informative in previous studies, $(6,8)$ but has not been validated. Other common cold instruments are available (e.g. Jackson score, WURSS-21), but none have been formally validated in children. Asthma is a disease of the lower airways, 
and our conclusions are based on samples obtained from the upper airway due to the age of the subjects and the need for serial sampling. Nevertheless, previous studies have shown correlations between upper and lower airway microbiology (27) and virology. (28) The nasal blow technique that was used could have underestimated rates of bacterial detection during periods of health; however in preliminary studies, nasal blow samples and mid-turbinate swabs yielded similar rates of bacterial detection (data not shown). Finally, these studies were conducted in suburban children during the month of September (2007, 2008 or 2009), and additional studies are needed to confirm our findings in other populations and at other times of the year.

Our findings suggest the possibility that prevention or treatment of S. pneumonia and $M$. catarrhalis could reduce the frequency and severity of respiratory illnesses, and importantly, exacerbations of asthma. Antibiotic treatment is available for these pathogens, but the benefits of this approach must be weighed against potential risks, such as antimicrobial resistance, killing of beneficial microbes, side effects, and cost. Uncomplicated colds are relatively minor and self-limited illnesses, and even if bacteria contribute to symptoms, antibiotic treatment is not warranted. Exacerbations entail greater morbidity, however, our data suggest that eight courses of antibiotics during colds would be required to prevent one asthma exacerbation. It is possible a subset of asthmatics would benefit from antibiotics, and further studies are needed to investigate this possibility. Other methods to prevent $S$. pneumonia and $M$. catarrhalis infections, such as vaccination and probiotics, are in use or development and could have efficacy for colds and exacerbations of asthma. In summary, our findings demonstrate that during the peak fall season RV infection increases the likelihood of detecting bacteria within the upper airway, and when detected along with $S$. pneumoniae or M. catarrhalis, children are at increased risk of experiencing illness symptoms and moderate asthma exacerbations. This association may help to explain why $\mathrm{RV}$ infections are associated with such a broad range of clinical illness. The implications of these findings are that solitary RV infections produce mild or asymptomatic infections, while RV infections that are complicated by secondary infection with (or expansion of) these airway bacteria cause more severe illnesses. If these findings are confirmed, understanding the mechanisms of RV/bacterial interactions could lead to new therapeutic approaches to respiratory illnesses and asthma.

\section{Supplementary Material}

Refer to Web version on PubMed Central for supplementary material.

\section{Acknowledgments}

The following NIH grants supported this research:

1. U19 AI070503-01 (RhinoGen)

2. P01 HL070831 (Childhood Origins of Asthma)

3. 1UL1RR025011 from the Clinical and Translational Science Award (CTSA) program of the National Center for Research Resources, National Institutes of Health

4. T32AI007635 (University of Wisconsin Allergy Research Training program) 
We greatly appreciate the efforts put forth by the clinical coordinators in patient recruitment, retention, and the procurement of all the biologic specimens used in these analyses. We also would like to acknowledge the cooperation of many health care professionals within our surrounding communities and the enthusiastic participation of the RhinoGen families.

\section{Abbreviations}
RV
Rhinovirus
PEF
peak expiratory flow
CFUe
colony-forming-unit equivalents
NHLBI
National Heart, Lung, and Blood Institute
ATS
American Thoracic Society
WURSS-21
Wisconsin Upper Respiratory Symptom Survey

\section{Reference List}

1. Bisgaard H, Hermansen MN, Buchvald F, Loland L, Halkjaer LB, Bonnelykke K, et al. Childhood asthma after bacterial colonization of the airway in neonates. The New England journal of medicine. 2007; 357(15):1487-95. Epub 2007/10/12. [PubMed: 17928596]

2. Bisgaard H, Hermansen MN, Bonnelykke K, Stokholm J, Baty F, Skytt NL, et al. Association of bacteria and viruses with wheezy episodes in young children: prospective birth cohort study. BMJ. 2010; 341:c4978. Epub 2010/10/06. [PubMed: 20921080]

3. Cardenas PA, Cooper PJ, Cox MJ, Chico M, Arias C, Moffatt MF, et al. Upper airways microbiota in antibiotic-naive wheezing and healthy infants from the tropics of rural Ecuador. PloS one. 2012; 7(10):e46803. Epub 2012/10/17. [PubMed: 23071640]

4. Hilty M, Burke C, Pedro H, Cardenas P, Bush A, Bossley C, et al. Disordered microbial communities in asthmatic airways. PloS one. 2010; 5(1):e8578. Epub 2010/01/07. [PubMed: 20052417]

5. Huang YJ, Nelson CE, Brodie EL, Desantis TZ, Baek MS, Liu J, et al. Airway microbiota and bronchial hyperresponsiveness in patients with suboptimally controlled asthma. The Journal of allergy and clinical immunology. 2011; 127(2):372-81. e1-3. Epub 2011/01/05. [PubMed: 21194740]

6. Olenec JP, Kim WK, Lee WM, Vang F, Pappas TE, Salazar LE, et al. Weekly monitoring of children with asthma for infections and illness during common cold seasons. The Journal of allergy and clinical immunology. 2010; 125(5):1001-6. e1. Epub 2010/04/16. [PubMed: 20392488]

7. Peltola V, Heikkinen T, Ruuskanen O, Jartti T, Hovi T, Kilpi T, et al. Temporal association between rhinovirus circulation in the community and invasive pneumococcal disease in children. The Pediatric infectious disease journal. 2011; 30(6):456-61. Epub 2011/01/05. [PubMed: 21200362]

8. Kloepfer KM, Olenec JP, Lee WM, Liu G, Vrtis RF, Roberg KA, et al. Increased H1N1 infection rate in children with asthma. American journal of respiratory and critical care medicine. 2012; 185(12):1275-9. Epub 2012/03/01. [PubMed: 22366048]

9. Lee WM, Grindle K, Pappas T, Marshall DJ, Moser MJ, Beaty EL, et al. High-throughput, sensitive, and accurate multiplex PCR-microsphere flow cytometry system for large-scale comprehensive detection of respiratory viruses. Journal of clinical microbiology. 2007; 45(8):2626-34. Epub 2007/06/01. [PubMed: 17537928]

10. Abdeldaim GM, Stralin K, Korsgaard J, Blomberg J, Welinder-Olsson C, Herrmann B. Multiplex quantitative PCR for detection of lower respiratory tract infection and meningitis caused by Streptococcus pneumoniae, Haemophilus influenzae and Neisseria meningitidis. BMC microbiology. 2010; 10:310. Epub 2010/12/07. [PubMed: 21129171]

11. Abdeldaim GM, Stralin K, Kirsebom LA, Olcen P, Blomberg J, Herrmann B. Detection of Haemophilus influenzae in respiratory secretions from pneumonia patients by quantitative real- 
time polymerase chain reaction. Diagnostic microbiology and infectious disease. 2009; 64(4):36673. Epub 2009/05/19. [PubMed: 19446978]

12. Greiner O, Day PJ, Altwegg M, Nadal D. Quantitative detection of Moraxella catarrhalis in nasopharyngeal secretions by real-time PCR. Journal of clinical microbiology. 2003; 41(4):138690. Epub 2003/04/12. [PubMed: 12682118]

13. Expert Panel Report 3 (EPR-3): Guidelines for the Diagnosis and Management of AsthmaSummary Report 2007. The Journal of allergy and clinical immunology. 2007; 120 (5 Suppl):S94138. Epub 2007/12/06. [PubMed: 17983880]

14. Proceedings of the ATS workshop on refractory asthma: current understanding, recommendations, and unanswered questions. American Thoracic Society. American journal of respiratory and critical care medicine. 2000; 162(6):2341-51. Epub 2000/12/09. [PubMed: 11112161]

15. Jackson DJ, Gangnon RE, Evans MD, Roberg KA, Anderson EL, Pappas TE, et al. Wheezing rhinovirus illnesses in early life predict asthma development in high-risk children. American journal of respiratory and critical care medicine. 2008; 178(7):667-72. Epub 2008/06/21. [PubMed: 18565953]

16. De Schutter I, Dreesman A, Soetens O, De Waele M, Crokaert F, Verhaegen J, et al. In young children, persistent wheezing is associated with bronchial bacterial infection: a retrospective analysis. BMC pediatrics. 2012; 12:83. Epub 2012/06/26. [PubMed: 22726254]

17. Dowell SF, Whitney CG, Wright C, Rose CE Jr, Schuchat A. Seasonal patterns of invasive pneumococcal disease. Emerging infectious diseases. 2003; 9(5):573-9. Epub 2003/05/10. [PubMed: 12737741]

18. Gray BM, Turner ME, Dillon HC Jr. Epidemiologic studies of Streptococcus pneumoniae in infants. The effects of season and age on pneumococcal acquisition and carriage in the first 24 months of life. American journal of epidemiology. 1982; 116(4):692-703. Epub 1982/10/01. [PubMed: 7137156]

19. Collazos J, de Miguel J, Ayarza R. Moraxella catarrhalis bacteremic pneumonia in adults: two cases and review of the literature. European journal of clinical microbiology \& infectious diseases: official publication of the European Society of Clinical Microbiology. 1992; 11(3):237-40. Epub 1992/03/01.

20. Short KR, Reading PC, Brown LE, Pedersen J, Gilbertson B, Job ER, et al. Influenza-induced inflammation drives pneumococcal otitis media. Infection and immunity. 2013; 81(3):645-52. Epub 2013/01/16. [PubMed: 23319557]

21. McCullers JA. Insights into the interaction between influenza virus and pneumococcus. Clinical microbiology reviews. 2006; 19(3):571-82. Epub 2006/07/19. [PubMed: 16847087]

22. Ruuskanen O, Lahti E, Jennings LC, Murdoch DR. Viral pneumonia. Lancet. 2011; 377(9773): 1264-75. Epub 2011/03/26. [PubMed: 21435708]

23. McCullers JA, Rehg JE. Lethal synergism between influenza virus and Streptococcus pneumoniae: characterization of a mouse model and the role of platelet-activating factor receptor. The Journal of infectious diseases. 2002; 186(3):341-50. Epub 2002/07/23. [PubMed: 12134230]

24. Harford CG, Leidler V, Hara M. Effect of the lesion due to influenza virus on the resistance of mice to inhaled pneumococci. The Journal of experimental medicine. 1949; 89(1):53-68. Epub 1949/01/01. [PubMed: 18099165]

25. Louria DB, Blumenfeld HL, Ellis JT, Kilbourne ED, Rogers DE. Studies on influenza in the pandemic of 1957-1958. II. Pulmonary complications of influenza. The Journal of clinical investigation. 1959; 38(1 Part 2):213-65. Epub 1959/01/01. [PubMed: 13620784]

26. Sajjan U, Wang Q, Zhao Y, Gruenert DC, Hershenson MB. Rhinovirus disrupts the barrier function of polarized airway epithelial cells. American journal of respiratory and critical care medicine. 2008; 178(12):1271-81. Epub 2008/09/13. [PubMed: 18787220]

27. Charlson ES, Bittinger K, Haas AR, Fitzgerald AS, Frank I, Yadav A, et al. Topographical continuity of bacterial populations in the healthy human respiratory tract. American journal of respiratory and critical care medicine. 2011; 184(8):957-63. Epub 2011/06/18. [PubMed: 21680950] 
28. Mosser AG, Vrtis R, Burchell L, Lee WM, Dick CR, Weisshaar E, et al. Quantitative and qualitative analysis of rhinovirus infection in bronchial tissues. American journal of respiratory and critical care medicine. 2005; 171(6):645-51. Epub 2004/12/14. [PubMed: 15591468] 


\section{Clinical Implications}

In children, co-detection of Rhinovirus with $S$. pneumoniae or $M$. catarrhalis leads to an increased risk of experiencing illness symptoms and moderate asthma exacerbations. 
A.

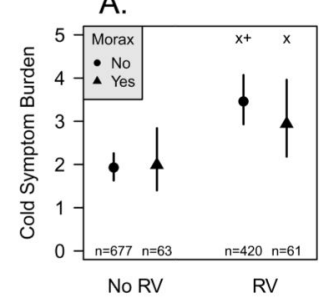

D.

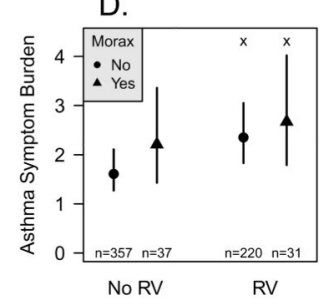

G.

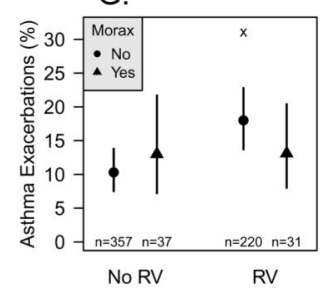

B.

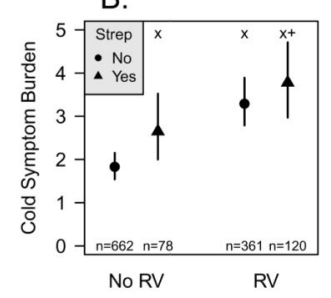

E.

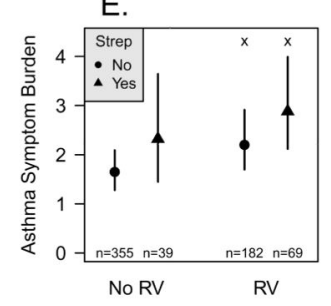

H.

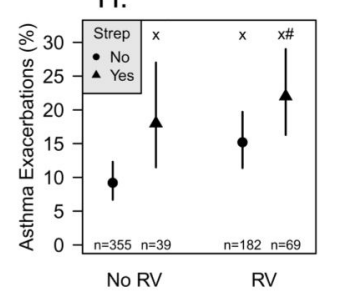

C.

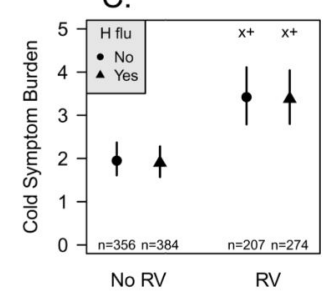

F.

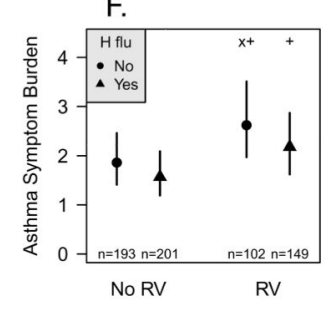

I.

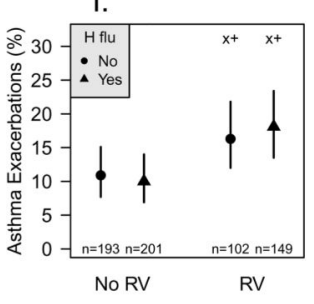

Figure 1.

Weekly pathogen detection compared to concurrent weekly respiratory symptoms. Weekly specimens of nasal secretions were analyzed for RV and bacteria, and pathogen detection was compared to weekly measures of respiratory symptoms, incuding $(\mathrm{A}-\mathrm{C})$ cold symptoms; (D-F) asthma symptoms; and (G-I) moderate asthma exacerbations. $\mathrm{x}$ : $\mathrm{p}<0.05$ vs. no pathogen, +: $\mathrm{p}<0.05$ vs. bacteria only, \#: $\mathrm{p}<0.05$ vs. RV only 

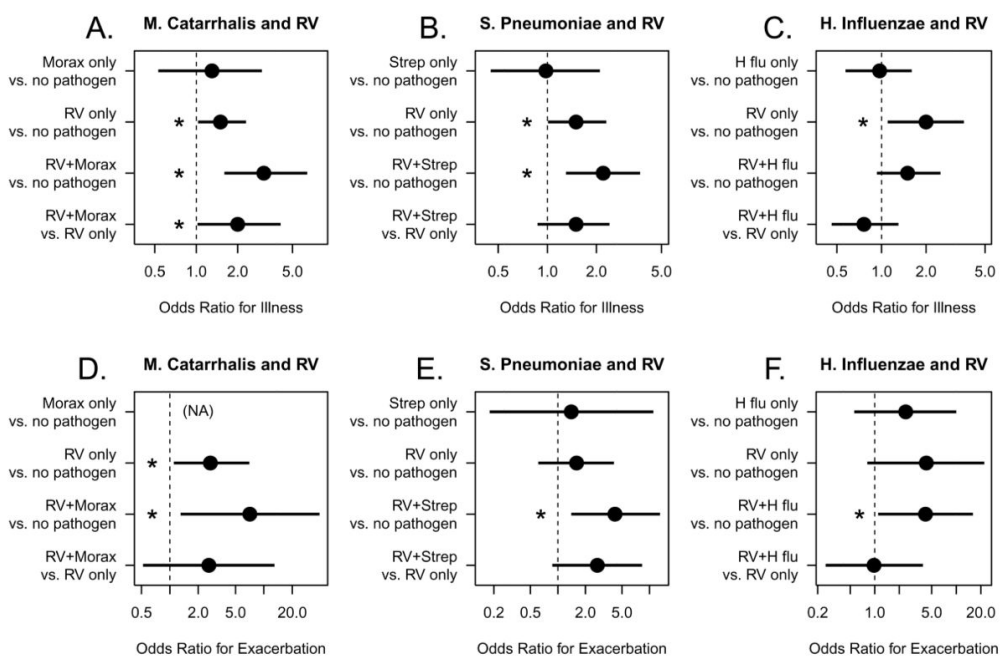

Figure 2.

Probability of experiencing illness symptoms according to patterns of pathogen detection (A-C). Each illness was matched with an asymptomatic period of the same length, and the probability of pathogen detection was compared. Within the asthma group, the probability of experiencing an asthma exacerbation with pathogen detection was also compared (D-F). $*$ :p $<0.05$ 


\section{Table 1}

Study subjects

\begin{tabular}{llll}
\hline & $\begin{array}{l}\text { Asthma } \\
\text { N=166 }\end{array}$ & $\begin{array}{l}\text { No asthma } \\
\text { N=142 }\end{array}$ & P-value \\
\hline Age (yrs) & $8.3 \pm 2.1$ & $8.6 \pm 1.6$ & 0.27 \\
Gender & $67 \% \mathrm{M}$ & $56 \% \mathrm{M}$ & 0.03 \\
Race & $81 \% \mathrm{C}$ & $92 \% \mathrm{C}$ & 0.007 \\
Atopic Status & $73 \%$ & $53 \%$ & 0.0003 \\
FeNO & $23 \pm 22$ & $13 \pm 13$ & $<0.0001$ \\
FEV1 & $1.71 \pm 0.44$ & $1.76 \pm 0.45$ & 0.31 \\
FVC & $2.12 \pm 0.59$ & $2.14 \pm 0.59$ & 0.99 \\
FEV1/FVC & $0.81 \pm 0.07$ & $0.83 \pm 0.07$ & 0.07 \\
\hline
\end{tabular}


Table 2

Detection of Bacteria and Virus in Relation to Asthma Status.

\begin{tabular}{llll}
\hline N=1,221 & No Asthma (N=576) & Asthma (N=645) & p-value \\
\hline No bacteria & $167(29 \%)$ & $187(29 \%)$ & 0.99 \\
M. catarrhalis & $56(10 \%)$ & $68(11 \%)$ & 0.64 \\
S. pneumoniae & $90(16 \%)$ & $108(17 \%)$ & 0.60 \\
H. influenzae & $308(53 \%)$ & $350(54 \%)$ & 0.78 \\
RV & $230(40 \%)$ & $251(39 \%)$ & 0.72 \\
\hline
\end{tabular}

$\mathrm{RV}=$ Rhinovirus 


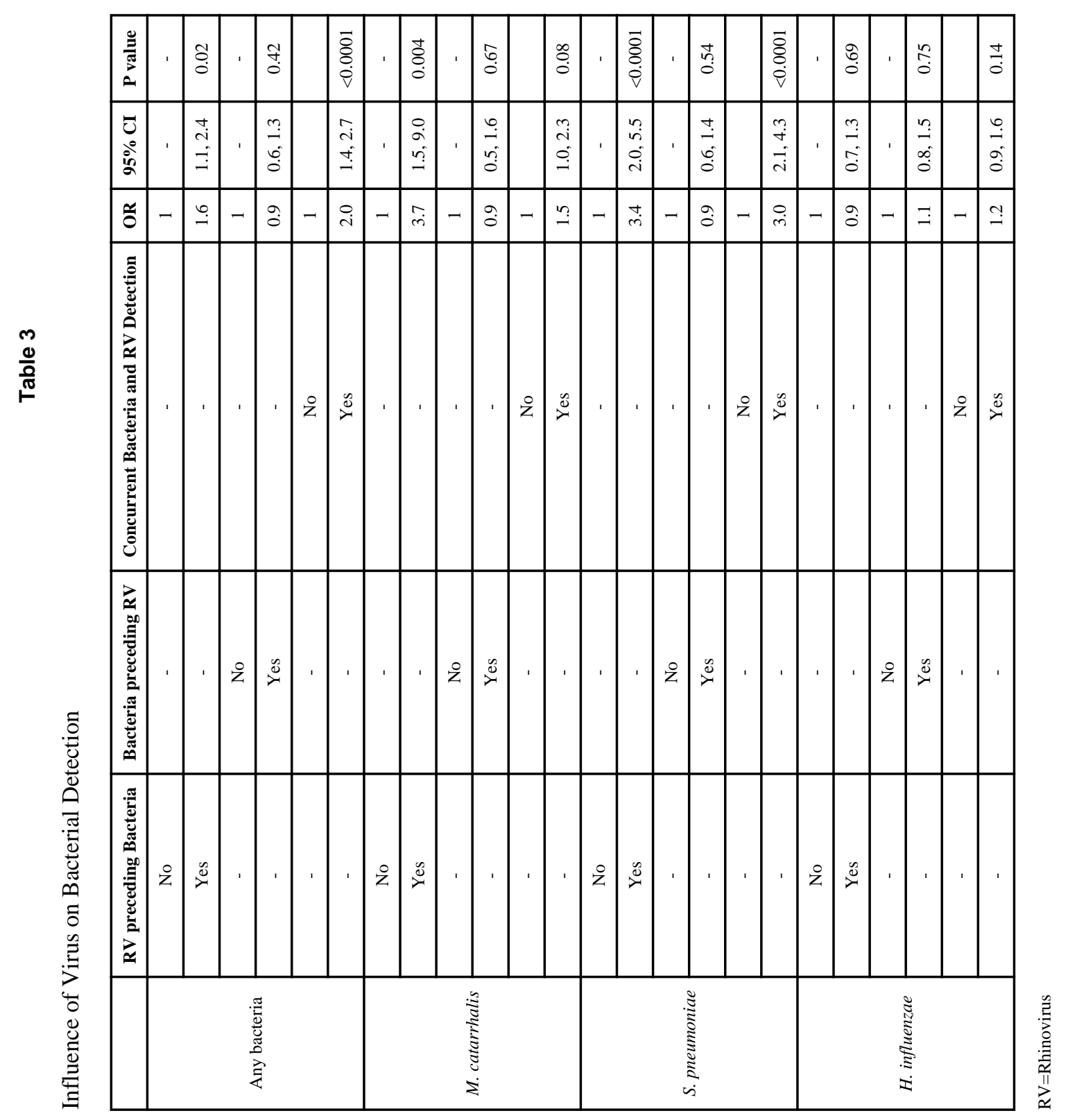

J Allergy Clin Immunol. Author manuscript; available in PMC 2015 May 01. 


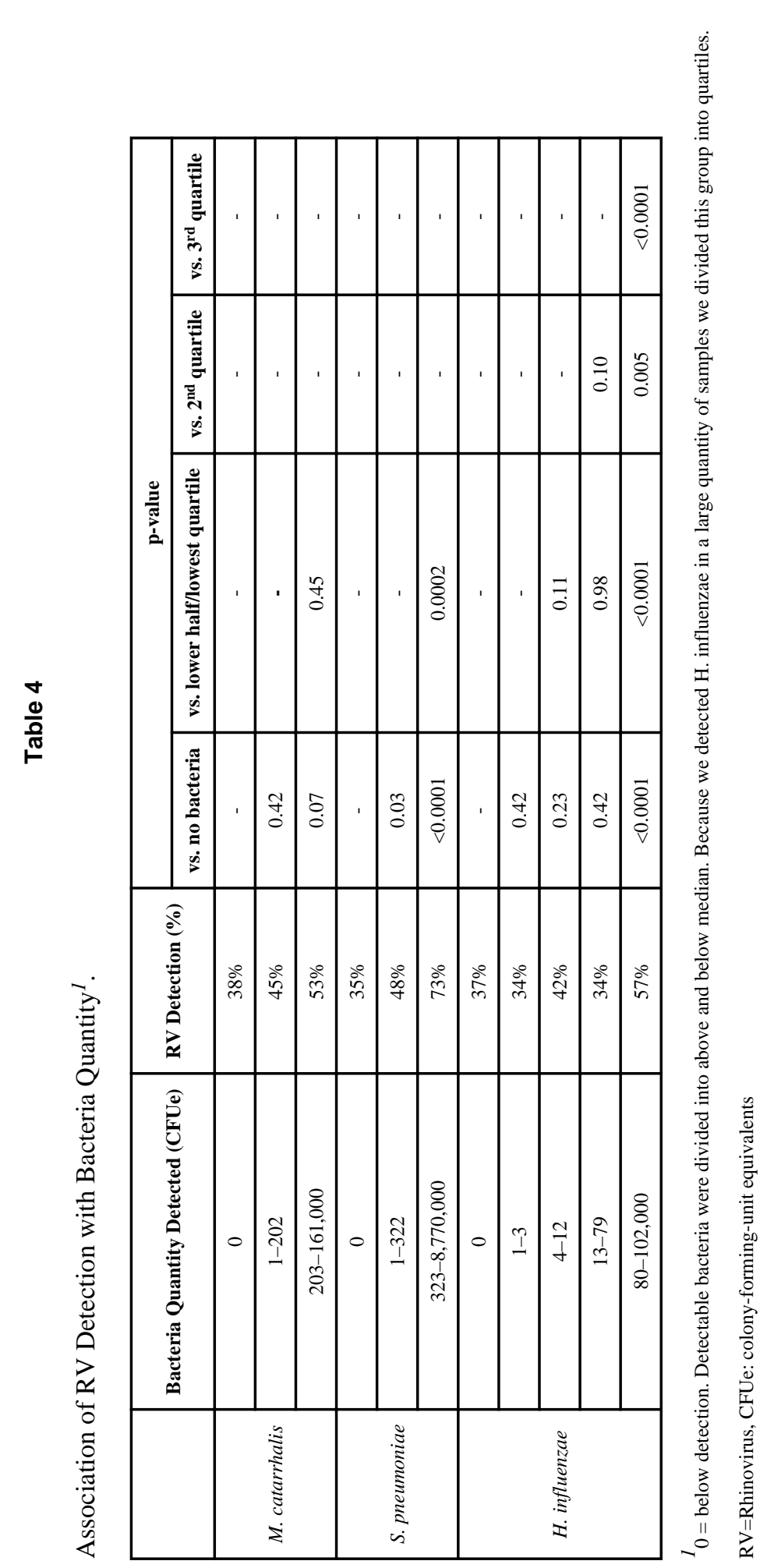

J Allergy Clin Immunol. Author manuscript; available in PMC 2015 May 01. 